\title{
Safety and quality in children anesthesia
}

\section{for gastroscopy}

\section{Damps Maria ${ }^{1}$, Stołtny Ludwik1ㅜ Kucewicz-Czech Ewa²}

${ }^{1}$ Department of anaesthesiology and intensive care, John Paul II Upper Silesian Child Health

Centre, Katowice, Poland

2 Department of anaesthesiology and intensive care with cardiac monitoring, Upper-Silesian

Medical Centre, Katowice, Poland

\section{BACKGROUND AND GOAL OF STUDY}

Finding combinations of drugs for safe anesthesia in children is still a challenge. The maintenance of respiratory and hemodynamic stability is the basis for safe anesthesia. The aim of this study was to compare and evaluate the use of ketamine-propofol versus remifentanilpropofol in children undergoing anesthesia for gastroscopy in terms of respiratory parameters and hemodynamic stability.

\section{MATERIALS AND METHODS}

\section{RESULTS}

Apnea and/or desaturation occurred in $8.8 \%$ of patients in both groups, was not significantly different. These events did not require any intervention. Study groups did not differ in pCO2 (44 \pm 4 in Group K vs. $44.5 \pm 5$ in Group R, p = 0.98). Hypercapnia occurred in $16(34.8 \%)$ of the subjects in Group K and in 18 (40.9\%) in Group R, without affecting the child's behavior after regaining consciousness $(p=0.7)$. None of the children had bradycardia and/or hypotension requiring intervention. Hemodynamic parameters are shown in the graphs.

\section{MEASUREMENT POINTS}

I - before induction

II - after induction

III - within 10 minutes after induction

IV - in the recovery room

The study included 90 children with ASA I risk, who were enrolled for elective endoscopy of the upper gastrointestinal tract under general anaesthesia (intravenous anesthesia with maintained spontaneous respiration and oxygen insufflation with a nasal cannula was used). The patients were randomized to one of the two groups: Group K consisted of children anaesthetized with propofol and ketamine, and Group $\mathrm{R}$ included children anaesthetized with propofol and remifentanil. Analysis included: saturation, apnea occurred, heart rate, systolic and diastolic blood pressure at four measurement points. At the end of gastroscopy, capillary blood gas was measured to evaluate $\mathrm{pCO}_{2}$ and $\mathrm{pO}_{2}$. Statistical analysis was performed using the STATISTICA 12 software.

Standard pharmacotherapy in both groups, including intervention doses

\begin{tabular}{|c|c|}
\hline Group K & Group R \\
\hline Induction: & Induction: \\
\hline Ketamine i.v., $1.5 \mathrm{mg} / \mathrm{kg} \mathrm{bw}$ & Remifentanil i.v., $0.1 \mu \mathrm{g} / \mathrm{kg} \mathrm{bw} / \mathrm{min}$. \\
\hline Propofol i.v. dose 1.5 mg/kg bw & Propofol i.v. 1.5 mg/kg bw \\
\hline Maintenance of anaesthesia: & Maintenance of anaesthesia: \\
\hline Propofol infusion 6 mg/kg bw/h & $\begin{array}{l}\text { Propofol infusion } 6 \mathrm{mg} / \mathrm{kg} \mathrm{bw} / \mathrm{h}+ \\
\text { remifentanil infusion } 0.1 \mu \mathrm{g} / \mathrm{kg} \\
\text { bw/min. }\end{array}$ \\
\hline $\begin{array}{l}\text { If necessary, an additional dose of } \\
\text { propofol i.v. } 0.5 \mathrm{mg} / \mathrm{kg} \mathrm{bw}\end{array}$ & $\begin{array}{l}\text { If necessary, an additional dose of } \\
\text { propofol i.v. } 0.5 \mathrm{mg} / \mathrm{kg} \text { bw }\end{array}$ \\
\hline
\end{tabular}

In $52.2 \%$ of children in both groups hyperoxygenation occurred

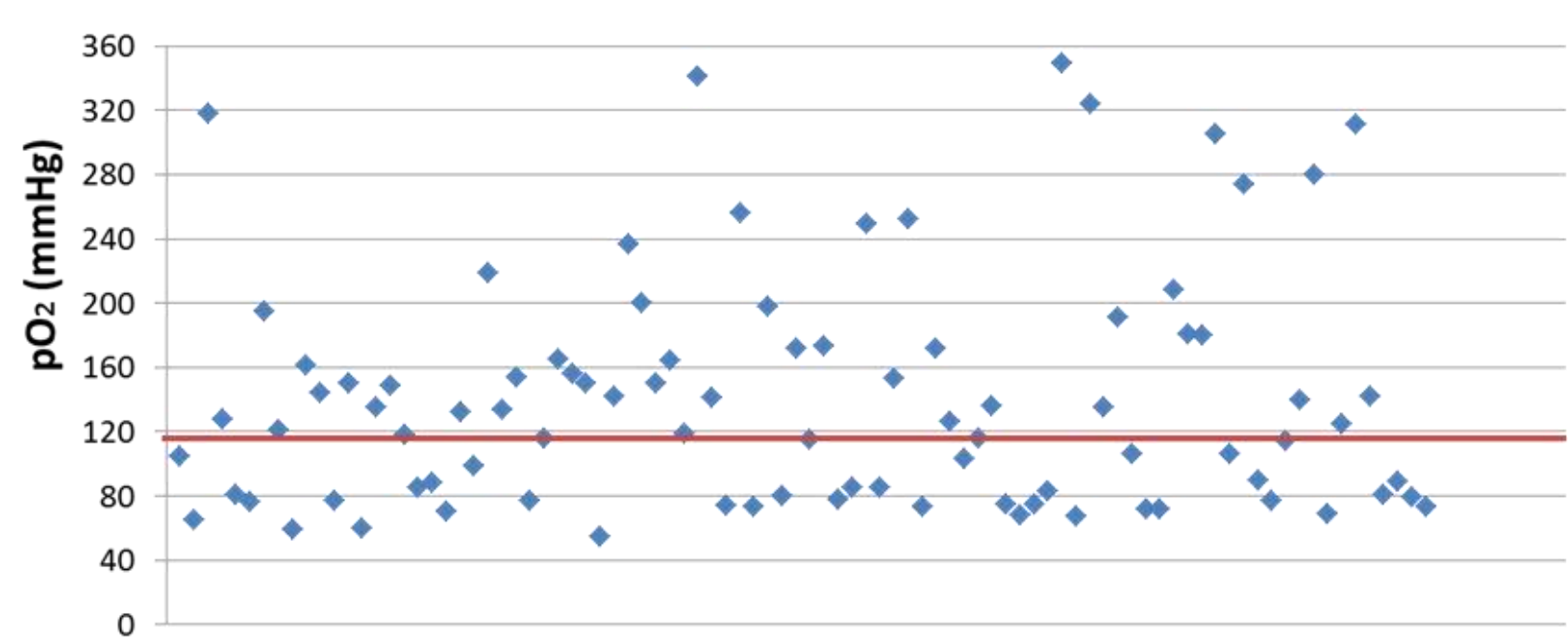

CONCLUSIONS

Both methods of anesthesia were characterized by maintained respiratory function and hemodynamic stability.

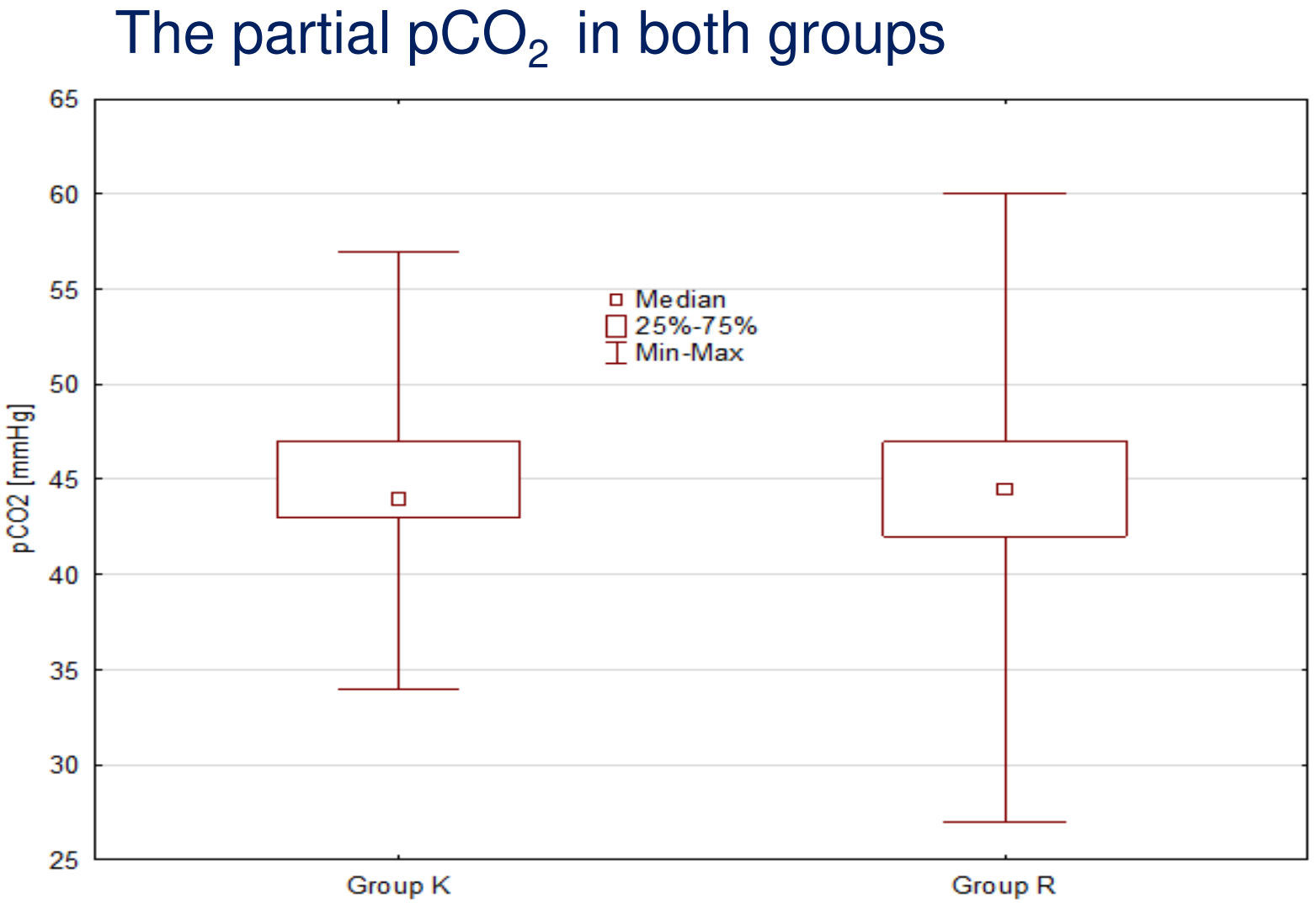

The heart rate at the measurment points, ${ }^{*} p<0,05$

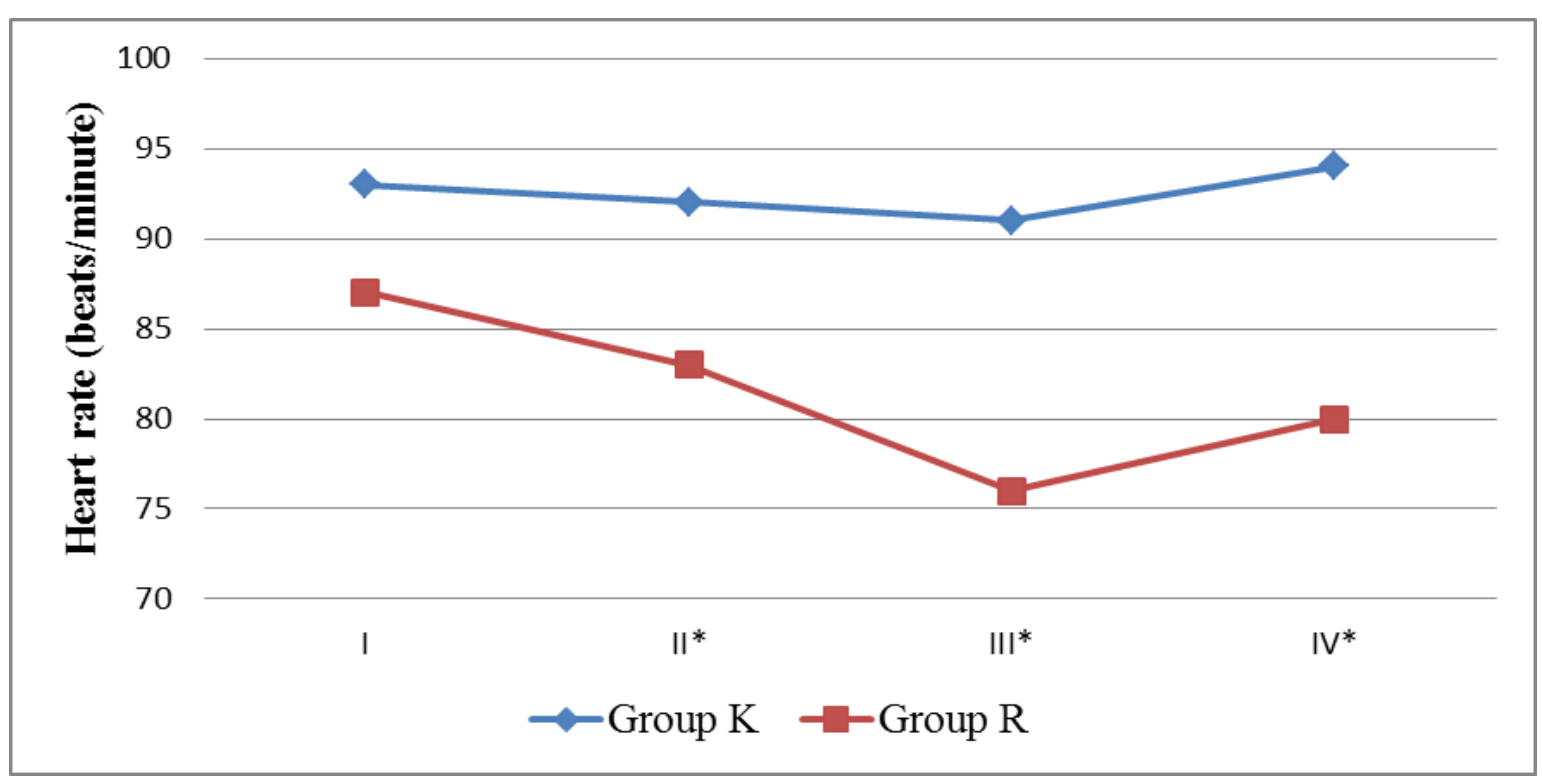

The SBP at the measurment points, ${ }^{*} p<0,05$

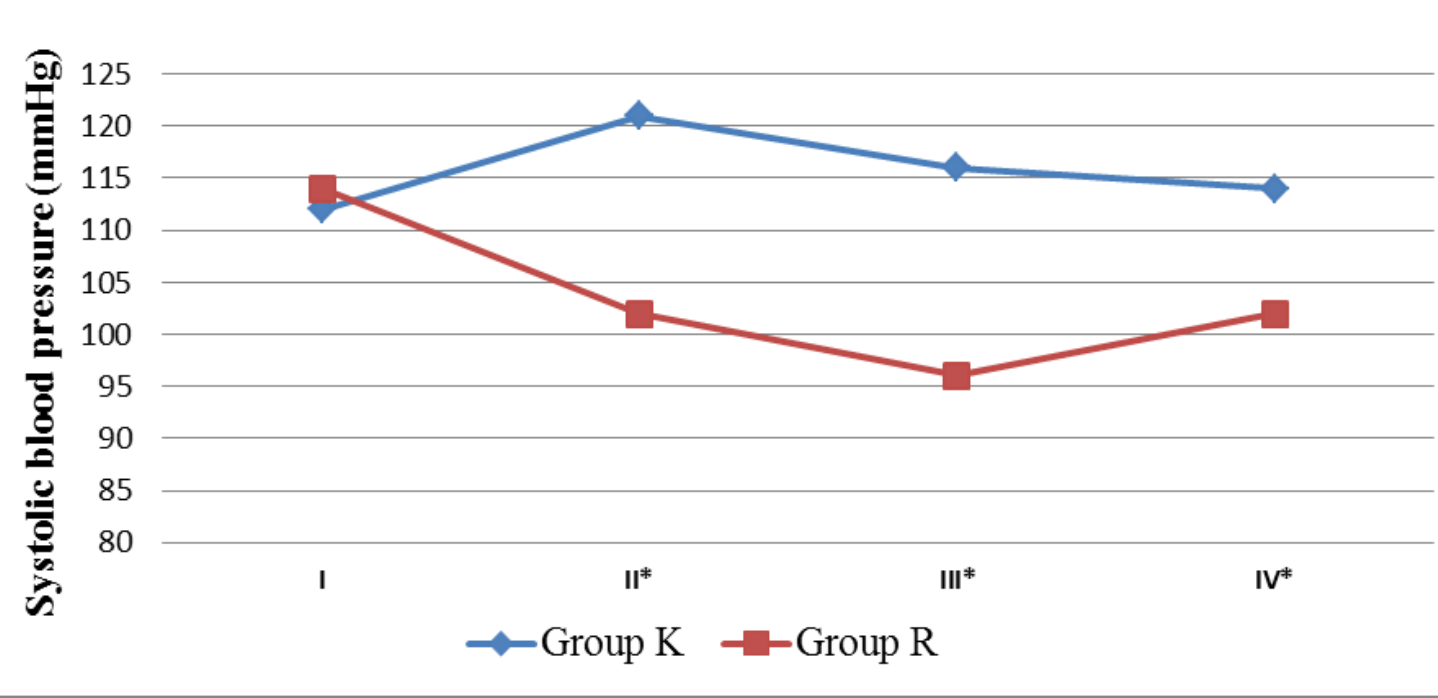

